David M. Ansley MD FRCPC, James G. Ramsay MD FRCPC, David G. Whalley MB FFARCS FRCPC, Judith M. Bent MB FFARCS, Robert Lisbona MD FRCPC, Vilma Derbekyan MD FRCPC, J. Earl Wynands MD FRCPC

\title{
The relationship between central venous pressure and pulmonary capillary wedge pressure during aortic surgery
}

Twenty-three ASA physical status II-III patients scheduled for elective abdominal aortic surgery were studied preoperatively with multiple unit gated acquisition angiography (MUGA) scan to determine the resting left ventricular and right ventricular ejection fractions (LVEF and RVEF respectively). Intraoperatively pulmonary capillary wedge pressure (PCWP) and central venous pressure (CVP) were measured in each patient at five different time periads in the horizontal, $24^{\circ}$ head up, and $24^{\circ}$ head down table tilt positions. The correlation berween absolute values and changes in PCWP and CVP, and the degree to which preoperative knowledge of LVEF and RVEF predicted these correlations were examined. Resting LVEF ranged from 0.1 to 0.84 . Thirreen of the 23 parients failed to show significant correlation $(p<0.05)$ between the absolute values of PCWP and CVP either before and/or after aortic crossclamp. When the correlation coefficients from this analysis were ranked against $L V E F$, there was a weak but significant correlation before aortic crassclamp $(r=0.4 I)$, but not after. The correlation between a change in PCWP and a change in CVP was significant for the 23 patienss at all time intervals, before and after aortic crossclamp. However, the prediction of a change of $P C W P$ value from a knowin change of CVP value ranged in accuracy from $\pm 3 \mathrm{mmHg}$ $10 \pm J 2.5 \mathrm{mmHg}$. The study suggests that if the filling pressures of both ventricles need to be assessed ditring aortic surgery, then the PCWP and CVP must be independently measured. Preoperative knowledge of LVEF and RVEF as determined by MUGA scan did not identify a subgroup of patients in whom $P C W P$ and CVP correlated consistently throughout aortic surgery.

\section{Key words}

SURGERY: abdominal aortic, measurement; TECHNIQUES: gated cardiac blocd pool scan; MONITORING: pulmonary artery flotation catheter.

From the Departments of Anaesthesia and Nuclear Medicine, Royal Victoria Hospital \& McGill University, Montreal, Quebec.

Address correspondence ro: Dr. David G. Whalley, Department of Anaesthesia, Room S5.05, Royal Victoria Hospital, 687 Pine Avenue West, Montreal, Quebec H3A IAI.
It has recently been suggested that a preoperative left ventricular ejection fraction (LVEF) of $>0.5$, determined angiographically, can predict a strong correlation between the central venous pressure (CVP) and the pulmonary capillary wedge pressure (PCWP) when "pre-load" is altered. ${ }^{1}$ A knowledge of preoperative LVEF can thus help determine the need for pulmonary artery catheterization during coronary artery surgery. ${ }^{1}$ It has been our experience, and that of others, that when the aorta is crossclamped during aortic surgery, the CVP and PCWP may no longer correlate. ${ }^{2}$ Clamping of the aorta may constitute an afterload stress which could provoke left ventricular dysfunction in a diseased heart, and it has not yet been determined whether a knowledge of the preoperative LVEF can predict a correlation between CVP and PCWP during aortic surgery.

A poor correlation has been demonstrated between CVP and PCWP when one ventricle is diseased and the other is not. ${ }^{3,4}$ This suggests that a knowledge of the preoperative function of both ventricles might help determine those patients in whom the filling pressures fail to correlate intraoperatively. Presently the two ventricles can be assessed separately with a multiple unit gated acquisition (MUGA) scan, ${ }^{5}$ thus avoiding the need for cardiac catheterization.

The purpose of this study was to determine if a correlation existed between PCWP and CVP during periods of changing preload and afterload in patients undergoing aortic reconstructive surgery. Specifically the study was designed to examine the relationship between PCWP and CVP during manipulation of preload by table tilt before and after aortic crossclamp in order to determine the effect of increased afterload on this relationship. In addition, the study evaluated the usefulness of preoperative MUGA scanning in predicting this correlation.

\section{Methods}

With the approval of the Hospital Ethics Committee, and 
following informed patient consent, 23 ASA physical status Class II-III patients underwent preoperative MUGA scanning. Normal values (mean \pm SD) for left ventricular ejection fraction (LVEF $=0.62 \pm 0.1$ ) and right ventricular ejection fraction (RVEF $=0.37 \pm 0.09$ ) were determined from a group of six healthy volunteers (mean age 38.25 years; range $30-55$ ). Patients with LVEF $\geq$ 0.52 were considered to have normal $\mathrm{LV}$ function, and those with LVEF $\leq 0.52$ below normal LV function.

All patients continued their cardiovascular medications to the time of surgery. In addition, they received a sedative premedication of diazepam $0.1 \mathrm{mg} \cdot \mathrm{kg}^{-1} \mathrm{PO}, 1 \frac{1}{2}$ hours preoperatively, and morphine $0.1 \mathrm{mg} \cdot \mathrm{kg}^{-1}$ and scopolamine $0.005 \mathrm{mg} \cdot \mathrm{kg}^{-1} \mathrm{IM}$, one hour preoperatively. Intravenous, radial artery and pulmonary artery catheters were inserted under local anaesthesia and a control set of haemodynamic values obtained.

Anaesthesia was induced with fentanyl $10 \mu \mathrm{g}^{-1} \mathrm{IV}$ and thiopentone to loss of consciousness. Muscle relaxation and tracheal intubation were achieved with pancuronium $0.1-0.15 \mathrm{mg} \cdot \mathrm{kg}^{-1}$ and the patient was ventilated to normocapnia. Anaesthesia was maintained with 70 per cent nitrous oxide and 30 per cent oxygen to which $0.5-1$ per cent halothane was added as necessary. The CVP was maintained at the control (awake) value with normal saline or lactated Ringer's solution and blood loss replaced with packed cells and fresh frozen plasma to maintain the haematocrit between $30-35$ per cent.

To produce changes in preload, the operating table was tilted to the head down 24 degrees position $\left(-24^{\circ}\right)$, and then to the head up 24 degrees position $\left(+24^{\circ}\right)$ with the pressure transducers continuously referenced to the right atrium. Stcady state measurements of PCWP and CVP were obtained in the horizontal, $-24^{\circ}$ and $+24^{\circ}$ positions at the following time intervals:

I Awake (control)

2 After the induction of anaesthesia (post-induction)

3 Before the application of aortic crossclamp (pre-crossclamp)

4 After the application of aortic crossclamp (post-crossclamp)

5 Immediately before the removal of aortic crossclamp (pre-declamp)

This protocol gave nine PCWP-CVP data points for each patient before aortic crossclamp (time intervals 1-3) and six data points after crossclamp (time intervals 4,5 ). The data for each patient in these two periods were analysed by linear regression (Regression Analysis I). The slopes of the relationships were compared before and after crossclamp, with paired Student's $t$ test. $P<0.05$ was considered significant.

In addition to recording the absolute values of PCWP and CVP, changes in these pressures were calculated when the patient went from $-24^{\circ}$ to $+24^{\circ}$ at each of the time intervals. Thus at each time interval, 23 data points were obtained. Data at each of these intervals were analysed by linear regression and the slopes of the regression lines obtained pre- and post-crossclamp (time intervals 3 and 4) were compared (Regression Analysis II). Ninety-five per cent confidence intervals for each relationship were then calculated so that the accuracy of predicting the change in PCWP from a given change in CVP could be determined.

To determine if the preoperative LVEF or RVEF could predict a significant relationship between PCWP and CVP, both linear regression and the Spearman rank correlation were obtained on the PCWP-CVP correlation coefficients and regression slopes from Regression Analysis I and the preoperative ejection fractions. ${ }^{6}$

\section{Results}

The patient demographic data are presented in Table I. There were 14 patients with normal LV function (Group I), and nine patients with abnomal LV function (Group II) as defined by the preoperative MUGA scan.

\section{Regression analysis I}

Figure 1 presents a typical regression analysis of a Group I patient. Table II presents the results of Regression Analysis I, ranked in ascending order of LVEF for each patient. Before aortic crossclamp the correlation between the absolute values of PCWP and CVP was statistically significant in 12 patients from Group I (12/14) and four

TABLE 1 Demographic data and clinical status (mean \pm SD where applicable

\begin{tabular}{lcc}
\hline & $\begin{array}{c}\text { Group }) \\
\text { (LVEF } \geqslant 0.52)\end{array}$ & $\begin{array}{l}\text { Group } / I \\
(\text { LVEF } \leqslant 0.52)\end{array}$ \\
\hline Age (yr) & $65 \pm 0.8$ & $63 \pm 0.3$ \\
Weight (kg) & $73 \pm 0.9$ & $66 \pm 0.3$ \\
Hcight (cm) & $172 \pm 0.4$ & $171 \pm 0.3$ \\
Body surface area $\left(\mathrm{m}^{2}\right)$ & $1.85 \pm 0.36$ & $1.76 \pm 0.3$ \\
Male & 13 & 7 \\
Fenale & 1 & 2 \\
& & $0.36 \pm 0.03$ \\
LVEF & $0.61 \pm 0.04$ & $0.30 \pm 0.03$ \\
RVEF & $0.39 \pm 0.04$ & 4 \\
Angina & 1 & 4 \\
Previous myocardial infarction & 1 & 2 \\
Congestive heart failure & 0 & 2 \\
Previous CABG* surgery & 1 & 2 \\
Other cardiac & $1 \dagger$ & 2 \\
Hypertension & 1 & $1 \neq$ \\
COPD & 1 & \\
\hline
\end{tabular}

* Coronary artery bypass graft.

$\dagger$ Atrial fibrillation.

†Mitral regurgitation. 


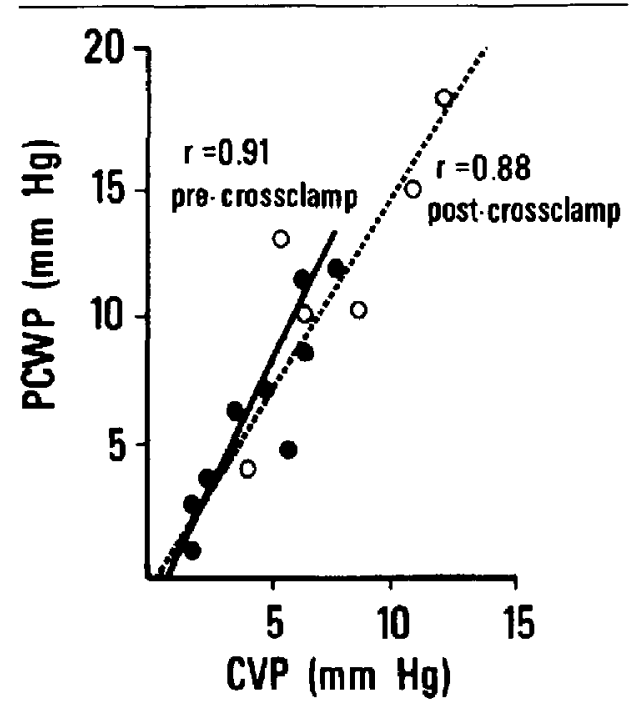

FIGURE 1 PCWP versus CVP in the pre-crossclamp (closed circles) and post-crossclamp (open circles) periods, for patient no. 1, Group 1. Both correlation coefficients are significant $(p<0.05$ ) patients from Group II (4/9). After aortic crossclamp the correlation was statistically significant for eight patients from Group I $\left(8 / 14 ; \chi^{2}=2.8, p>0.05\right)$ and seven patients from Group $\amalg\left(7 / 9 ; \chi^{2}=2.1, p>0.05\right)$. There was no significant difference ( $p>0.05$ ) between the slopes of regression lines before and after crossclamp for each patient, nor when the mean data was analysed for Group I, Group II or for both groups combined, suggesting that when a relationship did exist, the application of the aortic crossclamp did not significantly alter this relationship.

\section{Regression analysis II}

Table III presents the slopes and correlation coefficients for linear regression on the change in PCWP versus the change in CVP data at each time interval. In Table IV the 95 per cent confidence intervals at $x=\bar{X}$ indicate the minimum range of changes in PCWP possible from a given change in CVP. The data regression lines and confidence intervals for all patients are illustrated graphically in Figure 2.

Significant positive correlation at each time interval was obtained when the data from all patients and for Group I were examined. In Group II, the correlation

TABLE I] Regression Analysis I. Ejection fractions and regression of PCWP versus CVP for 23 patients before and after aortic crossclamp

\begin{tabular}{|c|c|c|c|c|c|c|}
\hline & \multirow[b]{2}{*}{$\angle V E F$} & \multirow[b]{2}{*}{ RVEF } & \multicolumn{2}{|c|}{ Before crossclamp } & \multicolumn{2}{|l|}{ After crossclamp } \\
\hline & & & Slope & $r$ & Slope & $r$ \\
\hline Group II & 0.1 & 0.14 & 1.37 & 0.62 (NS) & 2.33 & 0.94 \\
\hline 9 patients & 0.31 & 0.4 & 1.06 & 0.77 & 0.85 & 0.66 (NS) \\
\hline \multirow[t]{7}{*}{ LVEF $\leqslant 0.52$ ) } & 0.32 & 0.13 & 0.14 & 0.14 (NS) & 0.84 & 0.78 (NS) \\
\hline & 0.35 & 0.4 & 1.16 & 0.62 (NS) & 1.18 & 0.94 \\
\hline & 0.4 & 0.38 & 0.88 & 0.83 & 1.37 & 0.86 \\
\hline & 0.42 & 0.24 & 1.51 & 0.91 & 2.23 & 0.87 \\
\hline & 0.43 & 0.29 & 0.08 & 0.12 (NS) & 0.59 & 0.83 \\
\hline & 0.47 & 0.27 & 0.92 & 0.98 & 1.08 & 0.96 \\
\hline & 0.47 & 0.43 & 1.17 & 0.64 (NS) & 1.53 & 0.91 \\
\hline Group I & 0.5 & 0.31 & 1.45 & 0.91 & 1.21 & 0.88 \\
\hline 14 patients & 0.51 & 0.38 & 1.70 & 0.79 & 0.62 & 0.7 (NS) \\
\hline \multirow[t]{12}{*}{ LVEF $\geq 0.52$ ) } & 0.54 & 0.35 & 1.15 & 0.97 & 0.59 & 0.67 (NS) \\
\hline & 0.54 & 0.39 & 1.02 & 0.87 & 1.01 & 0.95 \\
\hline & 0.57 & 0.16 & 1.16 & 0.56 (NS) & 1.16 & 0.57 (NS) \\
\hline & 0.57 & 0.46 & 1.10 & 0.96 & 1.13 & 0.87 \\
\hline & 0.58 & 0.47 & 0.74 & 0.88 & 1.20 & 0.95 \\
\hline & 0.59 & 0.44 & 0.93 & 0.84 & -1.15 & 0.67 (NS) \\
\hline & 0.62 & 0.43 & 1.51 & 0.91 & 2.23 & 0.87 \\
\hline & 0.67 & 0.5 & 0.95 & 0.94 & 1.80 & 0.88 \\
\hline & 0.67 & 0.49 & 1.07 & 0.92 & 0.88 & 0.47 (NS) \\
\hline & 0.69 & 0.24 & 0.70 & 0.93 & 0.89 & 0.99 \\
\hline & 0.72 & 0.39 & 1.46 & 0.95 & 0.97 & 0.59 (NS) \\
\hline & 0.84 & 0.53 & 0.73 & 0.46 (NS) & 1.09 & 0.98 \\
\hline Group 11 mean $\pm \mathbf{S D}$ & & & $0.92 \pm 0.50$ & & $1.33 \pm 0.61(\mathrm{NS})$ & \\
\hline Group I mean $=S D$ & & & $1.05 \pm 0.28$ & & $0.97 \pm 0.75(\mathrm{NS})$ & \\
\hline All $(n=23)$ mean $\pm S D$ & & & $0.99 \pm 0.38$ & & $1.11 \pm 0.70(\mathrm{NS})$ & \\
\hline
\end{tabular}



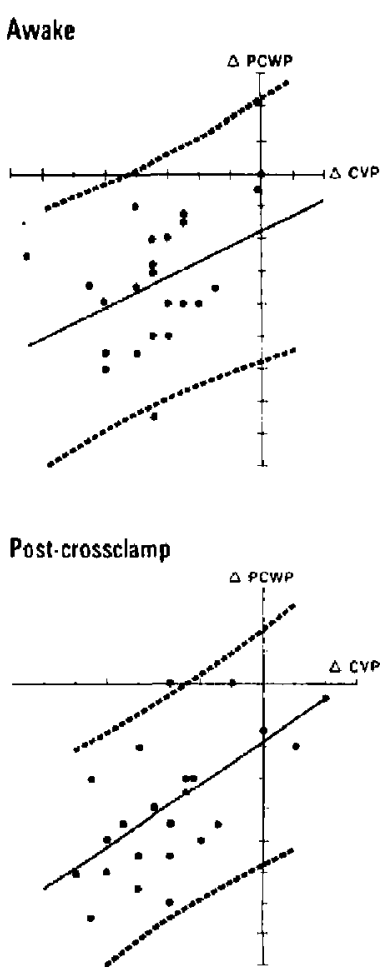

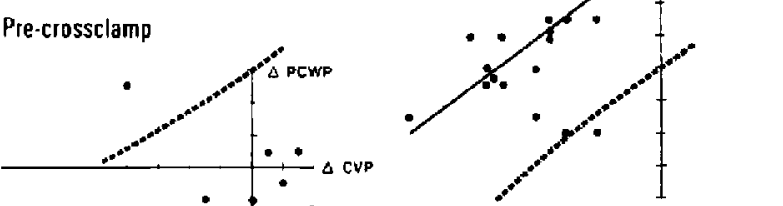

Pre-declamp

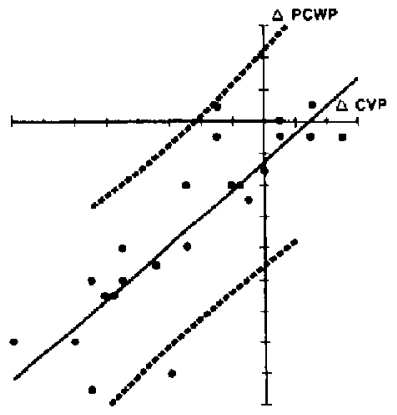

FIGURE $2 \triangle P C W P$ versus $\triangle C V P$ (solid line) and 95 per cent confidence intervals (dashed lines) for all patients in the awake, post-induction pre-crossclamp, post-cross clamp and pre-declamp periods. Fach mark on the axes is $2 \mathrm{mmHg}$. Despite significant correlation at each time, the 95 per cent confidence intervals are wide (Table IV).

coefficients failed to achieve significance at awake (control) and post-induction. Application of the aortic crossclamp did not significantly change the slope of the relationship between PCWP and CVP (Student's t test) for the study sample as a whole and for Group I. In Group II however, a significant negative correlation pre-crossclamp was transformed into a significant positive correlation post-crossclamp.

TABLE III Regression Analysis II. $\triangle$ PCWP versus $\triangle C V P$ with $\pm 24^{\circ}$ table tilt

\begin{tabular}{|c|c|c|c|c|c|c|}
\hline & \multicolumn{2}{|c|}{$\begin{array}{l}\text { All patients } \\
(n=23)\end{array}$} & \multicolumn{2}{|c|}{$\begin{array}{l}\text { Group I } \\
(n=14)\end{array}$} & \multicolumn{2}{|c|}{$\begin{array}{l}\text { Group } 11 \\
(n=9)\end{array}$} \\
\hline & Stope & $r$ & Slope & $\boldsymbol{r}$ & Slope & $r$ \\
\hline Awake & 0.46 & 0.41 & 0.58 & 0.69 & 0.83 & $0.34(\mathrm{NS})$ \\
\hline Post-induction & 0.72 & 0.73 & 0.76 & 0.84 & 2.03 & 0.57 (NS) \\
\hline Pre-crossclamp & 0.56 & 0.45 & 0.60 & 0.63 & -2.40 & -0.71 \\
\hline Post-crossclamp & 0.66 & 0.62 & 0.76 & 0.86 & 1.23 & 0.76 \\
\hline Pre-declamp & 0.86 & 0.85 & 1.29 & 0.78 & 1.45 & 0.90 \\
\hline
\end{tabular}

Even at those time intervals at which there was significant correlation between PCWP and CVP, the low correlation coefficients and wide confidence intervals indicated that estimation of a change in PCWP from a change in CVP was unreliable. In a small number of patients (those whose points fell outside of the upper right and lower left quadrants of the plots in Figure 2) the direction of change of PCWP was opposite to that seen with CVP.

TABLE IV 95 per cent confidence intervals for prediction of change in PCWP from a given change in CVP (mmHg) from Regression Analysis II $(\mathrm{x}=\overline{\mathrm{X}})$

\begin{tabular}{llll}
\hline & $\begin{array}{l}\text { All patients } \\
(n=23)\end{array}$ & $\begin{array}{l}\text { Group I } \\
(n=14)\end{array}$ & $\begin{array}{c}\text { Group II } \\
(n=9)\end{array}$ \\
\hline Awake & \pm 7.4 & \pm 6.8 & \pm 5 \\
Post-induction & \pm 7.2 & \pm 5.2 & \pm 3 \\
Pre-crossclamp & \pm 10.4 & \pm 5.4 & \pm 12.5 \\
Post-crossclamp & \pm 7.4 & \pm 6.5 & \pm 8 \\
Pre-declamp & \pm 6.4 & \pm 10.6 & \pm 8.2 \\
\hline
\end{tabular}




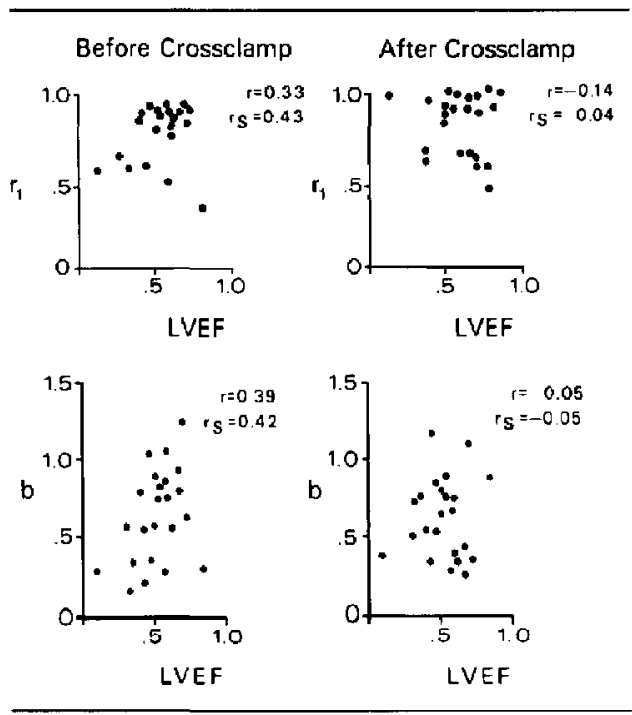

FIGURE 3 PCWP-CVP conrelation coefficients $\left(I_{1}\right)$ and slopes of the regression lines (b) from Regression Analysis I versus LVEF before and after aortic crossclamp. When linear regression is used to analyze this data, no statistically significant relationship is found $(r)$. The Spearman rank correlation coefficient $\left(\mathrm{r}_{\mathrm{s}}\right)$ is significant before aortic crossclamp, but only weakly $\left(\mathrm{r}_{\mathrm{s}}>0.4 \mathrm{I}=\mathrm{p}<0.05\right)$.

The relationship between the PCWP-CVP correlation coefficients and regression slopes from Regression Analysis $I$, and LVEF for all patients is presented in Figure 3. Linear regression revealed no significant correlation between the parameters examined either before or after aortic crossclamp. However, non-parametric statistical examination did reveal a weak but significant relationship between the PCWP-CVP correlation coefficients and regression slopes and LVEF pre-crossclamp. This association disappeared after the aortic crossclamp was applied. Similar analysis with RVEF failed to reach statistical significance at any time.

\section{Discussion}

The use of the pulmonary artery catheter (PAC) has introduced major questions of risk-to-benefit ratio which are still unresolved. In an attempt to minimize this risk-to-benefit ratio, various methods of preoperative assessment have been used to identify groups of patients in which the use of the PAC appears to be indicated.

The results of the present investigation demonstrate that in less than one half of the patients studied there existed a statistically significant correlation between absolute values of PCWP and CVP before and after aortic crossclamp. Alterations in preload or afterload (table tilting, aortic crossclamp) did not consistently change this relationship for these patients. The data were further analysed to see whether the correlation coefficients obtained before and after aortic crossclamp bore a significant relationship to preoperative LVEF. No such relationship was demonstrated using linear regression analysis but the Spearman rank correlation coefficient achieved significance before crossclamp. This finding deserves two comments. Firstly, the relationship between LVEF and the PCWP-CVP correlation coefficient is non-linear, which is not surprising when one considers that the distribution of the correlation coefficient itself is non-linear. Secondly, the coefficient of determination $\left(\mathrm{IS}_{\mathrm{S}}{ }^{2}\right)$ is only 18 per cent suggesting that, despite a significant correlation, 82 per cent of the variation in PCWP-CVP correlation was accounted for by causes other than the variability in LVEF. No significant relationship was demonstrated between the PCWP.CVP correlation coefficient and LVEF after the aortic crossclamp was applied suggesting the inadequacy of the preoperative LVEF in predicting that correlation.

In the accompanying editorial to the study by Mangano, Lowenstein pointed out the importance of the slope of the regression line in describing the relationship between CVP and PCWP. ${ }^{\top}$ A significant correlation does not predict the magnitude of the change in PCWP for a given change in CVP. Consequently we analysed the relationship between preoperative LVEF and the slope of the PCWP-CVP regression line and found a significant correlation before aortic crossclamp but not after. However, only the Spearman rank correlation coefficient was significant and the coefficient of determination was low, suggesting, as in the previous analysis, a non-linear relationship and other factors involved in this association.

Similar analyses using RVEF yielded no evidence of association. The study suggests that preoperative knowledge of RVEF and LVEF, as determined by MUGA scan, does not enable the identification of a group of patients in whom a monitor of the CVP can accurately be substituted for one of the PCWP.

There is much precedent in the scientific literature for the statistical approach used in this study for Regression Analysis I. However, there are a number of difficulties in analysing the relationship between PCWP and CVP before and after application of the aortic crossclamp. Regression analysis for each patient was calculated from data points not truly independent of each other and the study variable was confounded by the time elapsed since the induction of anaesthesia. In addition, two potential non-random sources of error were identified, namely, time interval and table tilt position. Consequently by recording changes in PCWP and CVP, calculated when the patient went from $-24^{\circ}$ to $+24^{\circ}$ of table tilt, 23 
independent data points at each time interval were obtained for Regression Analysis II. In these analyses, the correlation coefficients obtained at awake (control) and post-induction for Group II did not achieve significance, in contrast to those obtained for Group I or indeed when the data for all patients were considered (Table III). In addition, the slopes of the regression lines for Group II were large indicating substantial changes in PCWP for small changes in CVP. Most surprisingly in Group II, a significant ncgative correlation before aortic crossclamp was transformed into a significant positive comelation after aortic crossclamp. We are at a loss to explain this observation, but would suggest that this confirms the unpredictability of the PCWP-CVP relationship. Indeed in an attempt to quantify this unpredictability, the 95 per cent confidence intervals for a prediction of change in PCWP from a given change in CVP were calculated and are presented in Table IV and Figure 2. The range of values of $P C W P$ that can be obtained indicate that in some patients the CVP may reflect neither the degree nor direction of change of the corresponding PCWP. While recognizing that the widths of confidence intervals are inversely related to sample size, the extremes of PCWP that could be obtained make the information derived from the CVP potentially misleading. For example, if we consider a change in CVP of $5 \mathrm{mmHg}$ in Group II patients before aortic crossclamp, the predicted change in PCWP at the 95 per cent confidence interval is between -7.5 $\mathrm{mmHg}$ and $+17.5 \mathrm{mmHg}-\mathrm{a}$ clinically useless and potentially hazardous prediction.

Mangano found a close and clinically useful correlation between CVP and PCWP in patients undergoing coronary artery bypass grafting who had angiographically determined ejection fractions $>0.5 .^{\prime}$ Unfortunately, insufficient data were provided in that study to derive confidence limits of a composite slope for his group of patients. Studies on patients undergoing aortic surgery confirm our findings and suggest that the conclusions reached by Mangano cannot be generalized to the latter setting. Attia et al. identified a group of patients with severe coronary artery disease undergoing elective aortic surgery in whom the PCWP, but not the CVP, was significantly increased by application of the aortic crossclamp. ${ }^{8}$ Martin et al., in a study of 16 patients undergoing aortic bifurcation grafting found that the ejection fraction as determined preoperatively by gated cardiac scan could not isolate a patient subgroup for whom PA catheterization was not necessary. ${ }^{9}$ Gallacher et al. studied 18 patients undergoing elective aortic surgery to assess the value of preoperative nuclear angiography in identifying patients in whom CVP and PCWP correlate poorly. ${ }^{10}$ The CVP was considered to correlate with the PCWP if the difference between the two values was less than five torr and the two values changed in the same direction. On this basis, 60 per cent of patients with EF $<55$ per cent versus 25 per cent of patients with EF $>55$ per cent showed poor correlation. They would not modify the continued use of PA catheters in their patients on the basis of preoperative nuclear scans.

Our results and those of the latter studies may differ from those of Mangano for several reasons. Certainly there are inaccuracies inherent in the equipment used to collect data and limits to the applicability of an ejection fraction obtained in the resting state to the changing conditions of aortic surgery. As suggested by Martin el al. ${ }^{9}$ there may be a difference in the ejection fraction obtained angiographically (as in the study by Mangano) to that obtained by MUGA scan. Also important is the heterogeneity of our group of patients that included those with valvular heart disease, cardiomyopathy, COPD, hypertension and coronary artery disease. Measurements could be influenced by the presence of mitral regurgitation or cardiac arrhythmias such as atrial fibrillation, and our sample size may not have been large enough to detect differences between Groups (type II error). Finally, artificial manipulation of preload may not accurately reproduce changes in filling pressures that occur in the face of untreated myocardial ischaemia.

In conclusion, this study suggests that if the filling pressures of both ventricles need to be assessed during aortic surgery, then the CVP and PCWP must be independently measured. A knowledge of the preoperative ejection fraction cannot identify a group of patients in whom a monitor of the CVP accurately predicts the PCWP.

\section{References}

1 Mangano DT. Monitoring pulmonary arterial pressure in coronary artery disease. Anesthesiology 1980; 53: 364-70.

2 Rice $C L$, Hobeiman. CF, John DA et al. Central venous pressure or pulmonary capillary wedge pressuse as the determinant of fluid replacement in aortic surgery. Surgery 1978; 84: 437-9.

3 Forrester JS, Diamond G, McHugh TJ et al. Filling pressures in the right and left sides of the heart in acute myocardial infarction. N Engl J Med 1971; 285: 190-3.

4 Cohn JN, Tristiani FE, Khatri MM. Studies in clinical shock and hypotension. J Clin Invest 1969; 48: 2008-18.

5 Follard ED, Hamilton GW, Larson SM et at. The radionuclide ejection fraction: a comparison of three radionuclide techniques with contrast angiography. J Nucl Med 1977; 18: 1159-66.

6 Glantz SA. Primer of Biostatistics. New York: McGraw Hill, 1981 . 
7 Lowenstein E, Telplick R. To (PA) cathetcrize or not to (PA) catheterize - that is the question. Anesthesiology 1980; 53: 361-3.

8 Attia $R$, Murphy $D$, Snider $M$, et al. Myocardial ischemia due to infrarenal aortic crossclamping during aortic surgery in patients with severe coronary artery disease. Circulation 1976; 53: 961-5.

9 Martin $E$, Nicholas $G$, Osbakken $D$. Does pre-operative ejection fraction predict CVP/PCWP correlation during aortic surgery? Anesthesiology 1982; 3: A20.

10 Gallacher N, Goldberg J, Houston P, et al. The value of nuclear angiography in the pre-operative assessment of patients undergoing elective aortic surgery. Can Anaesth Soc J 1984; 31: 523-7.

\section{Résumé}

Nous avons mesuré la fraction d'éjection des ventricules droit et guuche, par ventriculographie isolopique, chez 23 patients de classe ASA I et II, devant subir une chirurgie de l'aorte abdominale. Durant l'opération, nous avons pris la tension veineuse centrale (TVC) at la pression d'occlusion de l'artère pulmonaire (POAP) chez tous les patients, a cinq moments différents, et ce en position horizontale, en trendelenbourg $\left(24^{\circ}\right.$, et en anti-srendelenbourg $\left(24^{\circ}\right)$. Noux avons cherché une corrélation entre les valeurs absolues de la TVC et de la POAP et leurs fluctuations respectives. On a tenté de prếdire des corrélations d la lumière des fractions d' éjection ventriculaires. Les valeurs de fraction d'sjection du ventricule gauche, au repos, s'étendaient de 0.1 a 0.85 . On n'a pas trouvé de corrélation ( $p<0.05$ ) chez 13 des 23 patients, entre les valeurs absolues de la POAP et de la TVC et ce avant, durant et après le clampage aortique. Nous avons identifié une corrélation entre les fluctuations du wedge et de la TVC chez les 23 patients. a tous les intervalles étudiés avant et aprés le clampage aortique. Les différences entre les valeurs mesurées de TVC et les valeurs prédites de POAP s'êtendaient de $\pm 3 \dot{a} 12.5 \mathrm{~mm} \mathrm{Hg}_{\mathrm{g}}$. Cente étude suggère que si les pressions de remplissage des deux ventricules doivent être evaluées au cours de la chirurgie de l'aorte, la tension veineuse et la tension pulmonaire de capillaire bloquée "wedge" doivent faire l'objet de mesure indépendante. De plus la connaissance des fractions d'éjection ventriculaires, avant l'opération, n'a pas permis d'identifier un sous groupe de patients chez qui on pouvait prédire de façon exacte la corrélation entre la TVC et la POAP. 